\title{
Ergonomic solutions to support forced static positions at work
}

\author{
Marcin Suszyński ${ }^{1}$, Marcin Butlewski ${ }^{2,}$, and Róża Stempowska ${ }^{2}$ \\ ${ }^{1}$ Poznan University of Technology, Institute of Mechanical Technology, Poland \\ ${ }^{2}$ Poznan University of Technology, Department of Ergonomics and Quality Engineering, Poland
}

\begin{abstract}
The article analyzes the available ergonomic constructions used for the support of the musculoskeletal system during static, prolonged work performed in forced positions. Possible evaluation methods are presented as well as ergonomic considerations of work performed in inclined positions, where there is no possibility of influencing the working plane. As a result of the presented work, a set of criteria has been proposed and the requirements for methods which can be used to evaluate the technical constructions supporting the worker during tasks performed in forced and static positions.
\end{abstract}

\section{Introduction}

Technological developments, and the resulting mechanization and automation of work processes have changed the nature of the demands placed on workers. Professions once characterized by dynamic physical loads, with high energy expenditures, are largely replaced by operator jobs and work requiring precision, where factors such as mental strain, work monotony, repetitive movements, static loads, and ultimately hypokinesia resulting from lack of motion are predominant. The latter two types of loads are to a large extent the main contributing factors to the nature of the work performed by highly qualified specialists such as mechanics, welders [1] or workers in medical professions (medical technicians, dentists, surgeons) [2]. The need to maintain unchanging and unnatural positions at work results in loads on the musculoskeletal system that lead to illnesses known as WRMSDs (work-related musculoskeletal disorders).

The remedial measures employed to prevent static loads are merely of an organizational or technical nature, none of them alone fully address the problem [3]. The problem of static positions is particularly important in those professions where, due to the nature of the work, the position cannot be effectively reorganized in such a way that a worker can assume a natural position at work or interrupt work to perform other tasks in order to relieve the musculoskeletal system. This would be the case for surgical work, where the life and health of the patient (human or animal) is more important than the welfare of the workers (technicians or doctors). The solution to such professions may be a variety of technical measures, however, for various reasons they may not meet the requirements based on which

\footnotetext{
*Corresponding author: marcin.butlewski@put.poznan.pl
} 
they were created. This article is therefore intended to provide an analysis of the ergonomic criteria for technical solutions that reduce static loads during work.

\section{Static positions and their ergonomic evaluation}

A static position is defined as any position where load on the musculoskeletal system is maintained for more than 4 seconds. However, a static work position is burdensome due to at least a few more reasons. The most important contributing factors are the following:

- number of body segments involved,

- combination of positions of body segments and the loads (expressed in $\mathrm{Nm}$ as the moment) put on reference joints by the body segments' weight and by the forces compressing and stretching these joints,

- influence of external forces resulting from the way the work is performed as well as the individual characteristics of the employee,

- extent to which a position is forced, resulting from the technical and organizational environment of the workplace,

- length of time to maintain a certain body position.

A very important factor when considering the burden of a static position is the length of time required to maintain it. It is evaluated using a parameter known as the percentage of maximum holding time (MHT). A load is considered acceptable if it lasts up to $20 \%$ of MHT [4]. MHT is calculated experimentally by determining the amount of time after which the study participant will be unable to continue maintaining a given static position. Along with a prolonged time of maintaining a position, static loads have an impact on the worker's capacity for physical effort - static muscle contractions result in changes in their biochemical composition, leading to increased fatigability and increased load on the musculoskeletal system.

The identification of non-recommended static positions is the subject of ergonomic standards such as ISO 11226, which allows for the evaluation of existing work situations, and EN 1005-4, suited for evaluations during the design/engineering process. In addition, a number of methods exist to assess the positions assumed at work - e.g. by evaluating loads on the whole body, such as OWAS (Ovako Working Posture Analysis System) [5], REBA - Rapid Entire Body Assessment [6], or QEC (Quick Exposure Check) [7]. Some of the methods are dedicated to certain types of loads - such as those on the upper limbs: RULA Rapid Upper Limb Assessment [8], or certain industries - as is the case for the Ergonomics Assessment Worksheet (EAWS), which is designed for manufacturing industries [9]. The listed methods are only a few selected from a large family of methods used in the risk assessment of WRMSDs, resulting from the manner and circumstances of the work.

Methods that are much more accurate, at least in terms of the classification of the position of the body, are computer simulations, which by modeling reality allow for a precise determination of hazard zones by providing an assessment of: body segment angles, hand locations and force magnitude, spine disc compression. Examples of such programs include 3-D Static Strength Prediction Program (3D SSPP), LifeMOD Biomechanics Modeller or BakPak Lift/Lowering Tasks. These programs are based on biomechanical calculations, and the accuracy of the obtained results is dependent on the extent to which the actual manner of operations was transferred to the virtual model. There are plenty of attempts to make the transition from real work situations to computer simulations [11].

To assess the consequences of static positions as well as the technical solutions (e.g. supports) designed to limit them, one can perform, among others, EMG studies [12] as well as studies employing thermography. Both methods examine muscle activity while assuming a certain position for a specified amount of time. Electromyography (EMG) is an experimental technique related to obtaining, recording, and analyzing specific myo- 
electrical signals. These signals arise due to physiological changes in the cell membranes of muscle fibers [13]. In addition to basic physiological and biomechanical research, EMG kinesiology can be used as an assessment tool in ergonomics (ergonomic design) research and in studies on the human body's interaction with industrial products and work conditions, which may form the basis for the verification of support prototypes. On the other hand, a study using a thermal imaging camera based on the imaging and analysis of infrared radiation emitted by the examined fragment of the body's surface allows the determination of the human body's interaction with the surface of the support measure. The variable impact of static positions and measures undertaken to reduce them requires a multi-criterial evaluation, by recognizing and interpreting both the actual and the predicted effects of the work performed.

\section{Technical solutions to reduce the burden of static positions}

Research on improving the ergonomic quality of work performed in forced, inclined and prolonged positions of the body has led to the development of solutions that reduce the risk of such loads. The result of these studies are seats equipped with additional elements (e.g. supports) to relieve the individual body segments or stabilizers supporting the standing position. Examples of such solutions are shown in Figure 1.
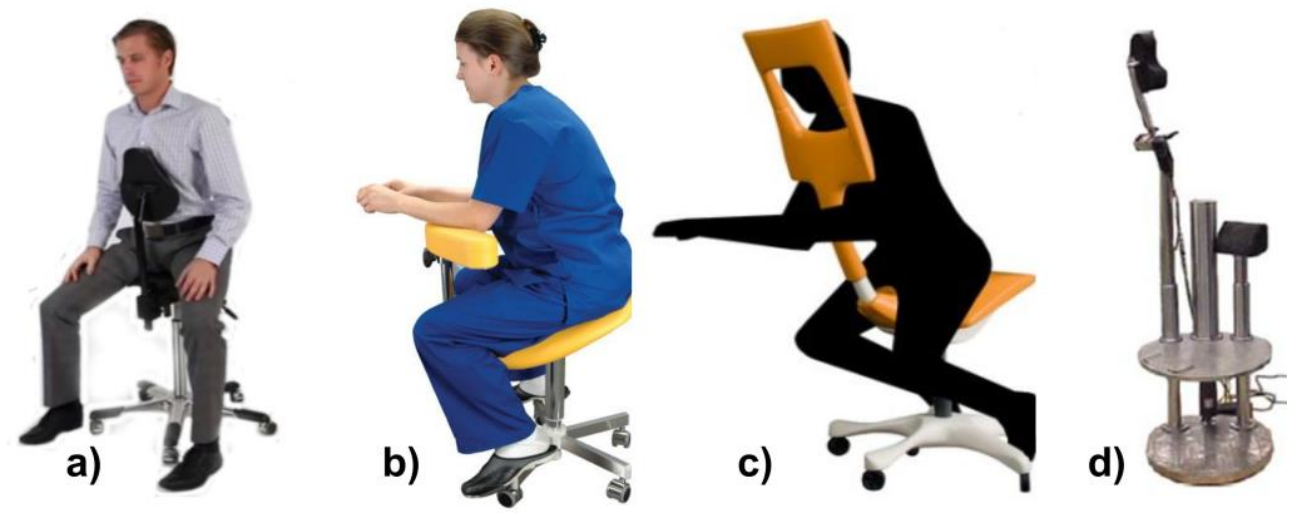

Fig. 1. Solutions supporting the maintenance of an inclined position [14-17].

The presented solutions' aim is to limit static loads, however, their overall ergonomic impact assessment also includes the determination of side effects such as point pressures on soft tissues and constraints on worker mobility associated with the use of the support. In order to assess their validity, their preliminary comparison was made for a surgeon performing laparoscopic procedures.

\section{Ergonomic evaluation of selected solutions reducing the impact of static positions}

As examples of a forced position at work, three methods of performing surgical tasks during laparoscopic procedures were considered. The most commonly assumed body position when performing such procedures is the standing position. It allows for a free range of movement and a stable position of the body, however, over time, it leads to the development of many ailments, causes fatigue and decreases work performance. Performing laparoscopic surgeries in the upright position involves a frequent tilt of the entire torso and head forward towards the operating plane. One reason for this is difficulties 
in adjusting the operating table height because of the large amount of space required for maneuvering laparoscopic equipment and long tools. On the other hand, performing laparoscopic surgery while seated requires physicians to maintain a natural lordosis because the use of such supports is not possible. In the seated position there is also the problem of the large distance required between the surgeon's position and the working plane due to the length of laparoscopic instruments. This contributes to excessive forward leaning and a loss of the natural lordosis, which in turn causes numerous ailments and discomfort during the performed work. A comparison was made of the estimated loads during the performance of laparoscopic surgery in three positions: (Figure 2)

A. standing position in close to ideal operating conditions (slight tilt),

B. unsupported sitting position with a tilt typical in this working position,

C. inclined sitting position, obtained when using alternative seating solutions.

Two computer programs, JACK and 3D SSPP, were used for the modeling of musculoskeletal load.

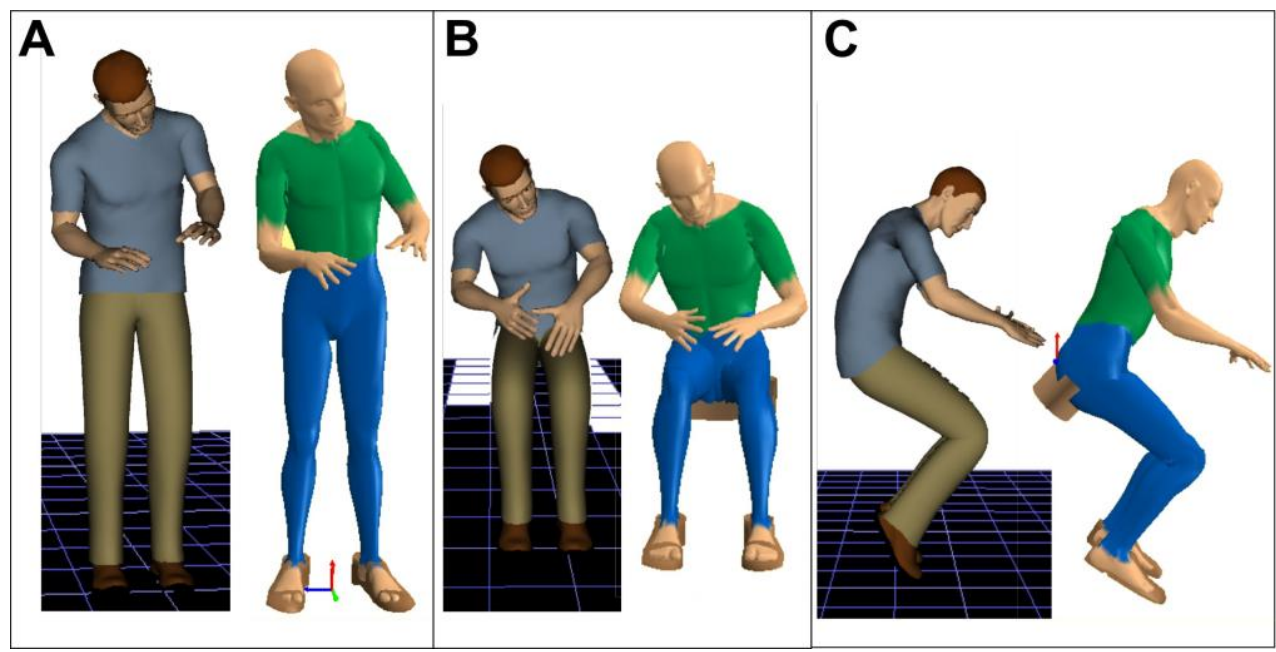

Fig. 2. Analyzed working positions.

The presented avatars represent the above-mentioned positions assumed by the surgeon during laparoscopic procedures. Both the 3D SSPP program and the JACK program are based on NIOSH data, which indicate the limit values for each parameter.

Table 1. Cooperation between positions

\begin{tabular}{|c|r|r|c|c|c|c|c|}
\hline \multicolumn{2}{|c|}{$\begin{array}{c}\text { Position/ } \\
\text { Program }\end{array}$} & \multicolumn{2}{|c|}{ Standing (A) } & \multicolumn{2}{c|}{$\begin{array}{c}\text { Unsupported } \\
\text { sitting (B) }\end{array}$} & \multicolumn{2}{c|}{$\begin{array}{c}\text { Alternative } \\
\text { sitting (C) }\end{array}$} \\
\cline { 3 - 9 } Biomechanical parameter & J-1 & 3D-1 & J-2 & 3D-2 & J-3 & 3D-3 \\
\hline \multicolumn{2}{|c|}{$\begin{array}{r}\text { Compression force on L4/L5 disc } \\
{[N]}\end{array}$} & 1973 & 1892,5 & 1045 & 2777,7 & 1205 & 2050,3 \\
\hline \multirow{3}{*}{$\begin{array}{c}\text { Percentage of the } \\
\text { population that is } \\
\text { able to transfer the } \\
\text { calculated moments } \\
\text { for each joint }\end{array}$} & Wrist & 97 & 92 & 93 & 87 & 100 & 98 \\
\cline { 2 - 9 } & Elbow & 100 & 100 & 100 & 98 & 100 & 100 \\
\cline { 2 - 9 } & Shoulder & 100 & 100 & 99 & 99 & 100 & 100 \\
\cline { 2 - 9 } & Torso & 99 & 97 & 99 & 95 & 100 & 99 \\
\cline { 2 - 9 } & Hip & 97 & 96 & 95 & 100 & 99 & 96 \\
\hline & Knee & 100 & 98 & 96 & 100 & 96 & 99 \\
\hline
\end{tabular}


Two indicators were used for biomechanical analysis: the compression force on the L4/ L5 intervertebral disc and the percentage of the population that is able to transfer the calculated moments for each joint. The postures of the individual avatars were modeled by defining the position of specific anthropometric points and by assigning angles of the specified joints.

The RULA scores indicate that the highest risk occurs in the sitting position. This level of risk is interpreted as: there is a need to introduce changes to the workstation. The alternative sitting position achieved the lowest average load, which should be interpreted as a sign for further research. It should be noted that the employed biomechanical models were consistent in their percentage results, but the L4/L5 forces indicated by the JACK and 3D SSPP programs differ markedly, despite identically modeled body positions. Both values were marked in the programs as green, which means they do not exceed the NIOSH limit values. The differences between the biomechanical evaluation and RULA scores may arise due to the simplified RULA scales (no exact values are given), as well as the method's greater focus on loads of the upper extremities. Certainly, the greater load will be indicated by the time required to maintain the position. At an incline of only $10^{\circ}$, the acceptable time of holding the static position is 10 minutes [18], and thus much shorter than the time needed for typical activities performed by laparoscopic surgeons.

Based on the data collected and the results obtained, it can be concluded that the most commonly used body position by laparoscopic surgeons contributes to the development of musculoskeletal disorders and changes need to be made to minimize this risk, and a solution in this regard may be the use of dedicated supports for lowering static loads. Solutions of this kind are all the more necessary since the acceptance of the negative impact of work on employees is decreasing [19], which means that only through ergonomic design can one make the appropriate modifications [20-23].

\section{Conclusions and recommendations for further research}

Ergonomic solutions, designed to limit the problem of static loads in the workplace, must be evaluated from the point of view of a number of factors, among them the main and most consequential is the reduction of the risk of developing WRMSDs. It should be noted, however, that in order for a solution to be considered ergonomic, the appropriate level of worker effectiveness must be ensured, through a proper range of movement and force generated during this movement, as well as a number of utilitarian requirements resulting from the environment in which the solution is used.

The performed analysis revealed the limitations of methods of biomechanical load evaluation that make it difficult to properly evaluate the solutions used to reduce the static loads on employees. The vast majority of methods fail to take into account the transfer of loads to parts of the body other than the limbs. In summary, when evaluating the effectiveness of applications and the ever-increasing number of solutions that support employee positions, one should employ more complex solutions, such as the program AnyBody. Most of common used ergonomic methods does not support alternative position at work.

\section{References}

1. A. M. Lasota, \& K. Hankiewicz, In 12th International Symposium on Occupational Safety and Hygiene of Portuguese-Society-of-Occupational-Safety-and-Hygiene (SHO), 261-264 (2016) 
2. N. Vujica Herzog, R. Vujica Beharic, A. Beharic \& B. Buchmeister, International Journal of Simulation Modelling (IJSIMM), 13(4) (2014)

3. A. Kawecka-Endler, B. Mrugalska, Advances in Social and Organizational Factors, , W. Karwowski Ed., 672-681 (2012)

4. L. Rose, M. Ericson, B. Glimskär, B. Nordgren, and R. Ørtengren, (omputer Applications in Ergonomics, Occupational Safety and Health, Mattila, M. and Karwowski, W., Eds., Amsterdam: Elsevier, pp. 461-468 (1992)

5. O. Karhu, Correcting working postures in industry: A practical method for analysis. Applied Ergonomics. 8(4), 199-201 (1977)

6. S. Hignett, \& L. McAtamney, Rapid entire body assessment (REBA). Applied ergonomics, 31(2), 201-205 (2000)

7. G. Li, P. Buckle, The development of a practical method for the exposure assessment of risks to work-related musculoskeletal disorders. General report to the HSE (Contract No. R3408), Robens Centre for Health Ergonomics, European Institute of Health and Medical Sciences, University of Surrey (1998)

8. L. McAtamney, E.N. Nigle Corlett,. RULA, Applied Ergonomics 24 (2), 91-99 (1993)

9. K.G. Schaub, J. Mühlstedt, B. Illmann, Bauer S., L. Fritzsche, T. Wagner, A.C. Bullinger-Hoffmann, R. Bruder, Int. J. Human Factors Modelling and Simulation, 3, Nos. 3/4 (2012)

10. G. Dahlke, Zeszyty Naukowe Politechniki Poznańskiej. Organizacja i Zarządzanie, 63, 21-32 (2014)

11. M. Butlewski, M. Sławińska, \& M. Niedźwiecki, Advances in Social \& Occupational Ergonomics 15-23. Springer International Publishing (2017)

12. A. Albayrak, Printer Partners Ipskamp, Enschede, ISBN/EAN: 978-90-5155-050-4 (2008)

13. J. Basmaijan, C. DeLuca, Muscles alive : their functions revealed by electromyography, Williams \& Wilkins (1985)

14. *** www.kos.ie

15. $* * *$ www.jedmed.com

16. *** walyou.com/blog/2010/08/01/unconventional-twist-chair

17. A. Albayrak, M. A. Van Veelen, J. F Prins, C. J. Snijders, , H. de Ridder, \& G. Kazemier,. Surgical endoscopy, 21(10), 1835-1840 (2007)

18. W. Karwowski, \& W. S. Marras, Occupational Ergonomics Reference Library-3 Volume Set: The Occupational Ergonomics Handbook (1998)

19. A.M. Lasota, K. Hankiewicz, Proceedings of the 2016 International Conference on Economics and Management Innovations, 57, 272-278 (2016)

20. A. Górny, Procedia Manufacturing, 3, 4700-4707 (2015)

21. A. Górny, Human Factor and Ergonomics in Essential Requirements for the Operation of Technical Equipment, in: C. Stephanidis (ed.), Posters Extended Abstracts: International Conference, HCI International 2014, Communications in Computer and Information Science, 435,. 449-454 (2014)

22. A. Kujawińska, K. Vogt, F. Wachowiak, Ergonomics as Significant Factor of Sustainable Production, in: P. Golińska, A. Kawa, (ed.), Technology Management for Sustainable Production and Logistics, Book Series: EcoProduction, 193-203 (2015)

23. A. Hamrol, D. Kowalik, A. Kujawinska, Human Factors and Ergonomics in Manufacturing \& Service Industries, 21(2), 156-163 (2011) 